\title{
Presença de Malassezia sp. em cães da Unidade de Controle de Zoonoses de Guaraí (TO) e sua relação com humanos
}

A Malassezia é uma levedura comensal em animais e humanos, foi encontrada no conduto da orelha externa de cães e gatos, mas também pode ser encontrado na pele de humanos, tanto na microbiota normal quanto na microbiota afetada. A patogenia dessa levedura está relacionada a um desequilíbrio da imunidade do hospedeiro ou associada há uma outra doença. Na década de 80, a infecção por Malassezia ganhou atenção na medicina humana devido a forma recorrente de dermatites seborreicas e pitiríase versicolor em humanos, a multiplicação dessa levedura se deu ao aumento de sebo e cerume, devido ao aumento da temperatura, umidade e fenda na pele. $\mathrm{O}$ exame apresentou uma incidência de Malassezia significativa, tanto na positividade, quanto na prevalência. No presente estudo fo evidenciado que $87 \%$ das lâminas positivas, $6,8 \%$ tiveram uma prevalência alta, seguido de $4,5 \%$ de prevalência moderada e de $2,2 \%$ de prevalência baixa. Sendo assim as espécies de Malassezia, a M. pachydermatis é a que mais acomete cães e humanos.

Palavras-chave: Malassezia; Levedura; Dermatite em Cães; Otites de Animais.

\section{Presence of Malassezia sp. in dogs of the Control Unit of Zoonoses of Guaraí (TO) and its relationship with humans}

\begin{abstract}
Malassezia is a commensal yeast in animals and humans, was found in the outer ear canal of dogs and cats but can also be found in the skin of humans, both in the normal microbiota and in the affected microbiota. The pathogenesis of this yeast is related to an imbalance of host or associated immunity to another disease. In the 1980s, Malassezia infection gained attention in human medicine due to the recurrent form of seborrheic dermatitis and pityriasis versicolor in humans, the multiplication of this yeast resulted in the increase of sebum and cerumen due to the increase in temperature, humidity and crevice skin. The examination had a significant incidence of Malassezia, both in positivity and in prevalence. In the present study it was evidenced that $87 \%$ of the positive slides, $6.8 \%$ had a high prevalence, followed by a moderate prevalence of $4.5 \%$ and a low prevalence of $2.2 \%$. Thus, being the species of Malassezia, M. pachydermatis is the one that most affects dogs and humans.
\end{abstract}

Keywords: Malassezia; Yeast; Dermatitis in Dogs; Animal Otitis.

Topic: Patologia Clínica e Laboratorial

Reviewed anonymously in the process of blind peer
Received: 05/11/2018

Approved: 11/02/2019
Lauriene Dias Rosa

Faculdade Guaraí, Brasil

http://lattes.cnpq.br/0759579930649683

dlauriene@gmail.com

Fabiana Teodoro Gomes

Faculdade Guaraí, Brasil

http://lattes.cnpq.br/4031908089594053

fabianabmed@gmail.com

Thainara Anjos Barros

Faculdade Guaraí, Brasil

http://lattes.cnpq.br/6580256274245989

thainara-barros96@hotmail.com
Aluísio Vasconcelos de Carvalho (iD

Faculdade Guaraí, Brasil

http://lattes.cnpq.br/5200758055263996

http://orcid.org/0000-0002-3793-3133

aluisiovasconcelos@gmail.com

DOI: 10.6008/CBPCxxxx-xxxx.2019.001.0001

Referencing this:

ROSA, L. D.; GOMES, F. T.; BARROS, T. A.; CARVALHO, A. V.. Presença de Malassezia sp. em cães da Unidade de Controle de Zoonoses de Guaraí (TO) e sua relação com humanos. Health of Humans, v.1, n.1, p.1-8, 2019. DOI: http://doi.org/10.6008/CBPCxxxxxxxx.2019.001.00xx 


\section{INTRODUÇÃO}

O gênero Malassezia, identificada inicialmente por Baillon em 1889, abrange leveduras lipofílicas e lipodependentes que pertencem à microbiota natural de seres humanos e de animais (SCHLOTTFELDT et al., 2002). É uma levedura comensal em animais e humanos, que raramente acomete patogenia. $O$ gênero Malassezia possuem em torno de 13 espécies, destas, 12 são lipodependentes (M. furfur, M. globosa, $M$. obtusa, M. restricta, M. sloofiae, M. sympodialis, M. dermatis, M. nana, M. japonica, M. yamatoensis, $M$. eqüina sp. nov., M. caprae sp. nov.), e com ressalva da espécie $M$. pachydermatis que não é lipidodependente, porém é a mais envolvida nas dermatites e otites de animais. Essa levedura é encontrada no conduto da orelha externa de cães e gatos, mas também pode ser encontrado na pele de humanos, tanto na microbiota normal quanto na microbiota afetada (MELCHERT et al., 2011).

Apesar das espécies de Malassezia serem bastante similares entre si, sua diferenciação se dá através da avaliação morfofisiológica, é possível perceber as diferenças na micromorfologia específica de cada espécie como a atividade enzimática, as necessidades nutricionais e critérios moleculares. Para diferenciá-las morfofisiologicamente faz-se necessário o cultivo em meio de Dixon modificado a $32^{\circ} \mathrm{C}$ durante sete dias (SCHLOTTFELDT et al., 2002).

Nestas condições de culturas, as espécies apresentam diferentes características morfológicas tornando difícil de identificá-las a nível de espécie apenas pelo parasitológico, isso porque a Malassezia furfur pertence a microbiota habitual da pele dos seres humanos, cresce na presença de lipídio, com temperatura ótima de $32^{\circ} \mathrm{C}$, mas pode haver crescimento até $41^{\circ} \mathrm{C}$. As colônias têm aspecto cremoso, friáveis (facilidade para se desmanchar), convexas e de coloração branco fosco (MELCHERT et al., 2011; SCHLOTTFELDT et al., 2002). Ao microscópico pode observar células com tamanhos e formas variadas, ovais, esféricas ou cilíndricas. A M. furfur possui três formas de infecções superficiais no homem, a pitiríase versicolor, foliculite e dermatite seborreica, pode se manifestar em infecções sistêmicas em recém-nascidos prematuros e em adultos imunocomprometidos (MARASCHIN et al., 2008).

As colônias de Malassezia pachydermatis tem aparência fosca, cremosa e macia ou friável. Sua morfologia apresenta células ovais pequenas com brotamento sem filamentos, com $37^{\circ} \mathrm{C}$ de temperatura perfeita, porém pode se desenvolver em $40^{\circ} \mathrm{C}$ ou $41^{\circ} \mathrm{C}$. É uma espécie zoofílica, entretanto já foi relatada sua presença em neonatos com fungemia e em cães causa otites (GUILLOT et al., 1999; MARASCHIN et al., 2008; MCVEY et al., 2013).

Sugita et al. $(2003 ; 2004)$ mostram em seus trabalhos que a melhor forma de identificação das espécies de M. japonica e da M. yamatoensis são por PCR (Polymerase Chain Reaction) Reação em cadeia da polimerase, por que nesse processo a diferenciação das espécies é feita pela sequência do DNA, já que suas morfologias microscópicas e de culturas são bem semelhantes com outras espécies de Malassezia (LEITE, 2016; HIRAl et al., 2004; SUGITA et al., 2004). A definição de novas espécies de Malassezia ajuda a compreender as dermatoses e suas associações (MARASCHIN et al., 2008). 
Como essa levedura é encontrada em animais debilitados, sua patogenia está relacionada a um desequilíbrio da imunidade do hospedeiro ou associada há uma outra doença, como por exemplo, mudanças no microambiente, aumento na temperatura, umidade e nutrientes, e essa mudança propicia o aumento das células deixando de ser levedura comensal para a forma patogênica (SANTIN et al., 2014).

Devido a Malassezia fazer parte da microbiota normal dos animais, sua alta prevalência causando patogenia vai variar de acordo com a imunidade e com outras patologias que acometem os animais, como otites e/ou dermatites (PRADO et al., 2007).

Na década de 80, a Malassezia ganhou atenção na medicina humana devido à forma recorrente de dermatites seborreicas e pitiríase versicolor. O que favorece sua multiplicação em humano é o aumento na produção de sebo ou cerume, umidade alta e/ou fenda na barreira epidérmica, mas a sua contaminação para a pele humana se dá pela transferência da Malassezia pachydermatis da pele do animal, segundo alguns estudos (TÁRTARA, 2011).

Nos humanos, as espécies de Malassezia também pertencem à microbiota normal da pele. Habitualmente, nos folículos pilosos de regiões seborreicas e com a existência de lípides, a levedura se torna parasitária, como uma pseudo-hifa (FRAMIL et al., 2010). Sua maior periodicidade se dá na puberdade devido às alterações lipídicas da pele pelas modificações hormonais, e estão associadas com várias patologias cutâneas e sistêmicas, tais como, pitiríase versicolor, dermatite seborreica, dermatite atópica e fungemia (MARASCHIN et al., 2008, NOBRE et al., 1998; SANTIN et al., 2010).

A prevalência de dermatite seborreica no homem adulto é elevada, e sua presença causa incômodos devido a formação de prurido, odor e aspecto desagradável, especialmente na face e couro cabeludo. Estudos comprovam que essas dermatoses acarretam grande abalo emocional no convívio social e nas atividades diárias dos pacientes, em motivo do visual das lesões (BRAZ et al., 2014).

A leishmaniose canina está ligada ao aumento in vitro da Malassezia, e como há um aumento significativo de leishmaniose em Guaraí (TO), consequentemente haverá um aumento nos casos de Malassezia nos animais e assim acometendo os humanos, por não ser muito conhecida, passa despercebida e eleva o número das dermatites.

O objetivo deste trabalho é verificar a presença de Malassezia sp. em cães da Unidade de Controle de Zoonoses de Guaraí (TO).

\section{MATERIAL E MÉTODOS}

Foram coletadas 15 amostras de cães de ambos os sexos, com idade de 1 a 10 anos, de diversas raças, já diagnosticados com leishmaniose através do teste rápido. Esses cães estavam alojados na Unidade de Controle de Zoonoses do município de Guaraí (TO). A coleta foi realizada no período de agosto a setembro de 2018. O exame realizado para Malassezia foi através do micológico direto, a amostra foi coletada do conduto auditivo dos cães com o auxílio do swab (Figura 1). A amostra foi delicadamente depositada com movimentos rotacionais diretamente na lâmina (Figura 2), depois fixado com álcool metílico e corado com Giemsa. 


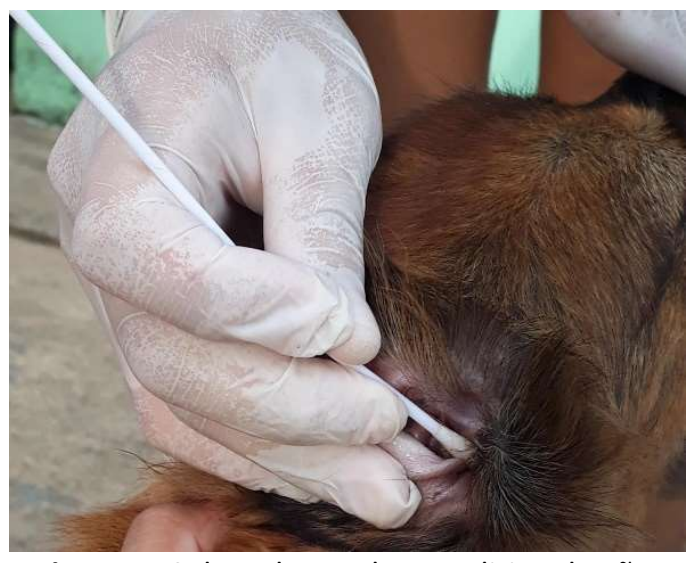

Figura 1: Coleta do conduto auditivo do cão.

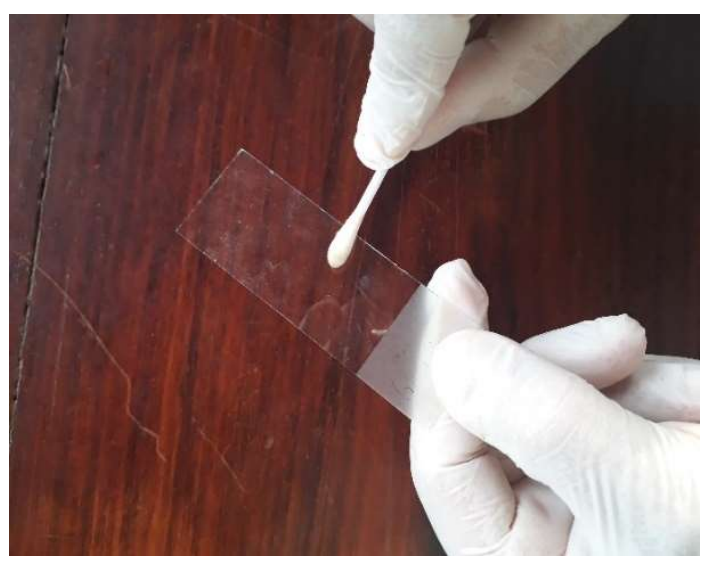

Figura 2: Amostra sendo colocada na lâmina.

As lâminas foram observadas ao microscópio em aumento de 40x e depois de 100x para confirmação das formas parasitárias, onde foi visualizadas brotamento único em formato oval com fixação de base larga, formato característico de "marca de sapato" (MCVEY et al., 2013).

\section{RESULTADOS E DISCUSSÃO}

Após a análise das amostras coletadas de 15 indivíduos, observou-se que $87 \%$ estavam positivas para Malassezia. A parasitemia diferenciou significativamente entre os indivíduos amostrados (Tabela 01).

Tabela 01: Cães positivos para Malassezia coletados na Unidade de Controle de Zoonoses.

\begin{tabular}{|c|c|c|}
\hline INDIVÍDUO & RESULTADO & PARASITEMIA \\
\hline 01 & Positivo & ++ \\
\hline 02 & Positivo & ++ \\
\hline 03 & Positivo & ++ \\
\hline 04 & Positivo & ++ \\
\hline 05 & Positivo & ++ \\
\hline 06 & Positivo & + \\
\hline 07 & Negativo & + \\
\hline 08 & Negativo & + \\
\hline 09 & Positivo & ++ \\
\hline 10 & Positivo & ++ \\
\hline 11 & Positivo & ++ \\
\hline 12 & Positivo & ++ \\
\hline 13 & Positivo & ++ \\
\hline 14 & Positivo & + \\
\hline
\end{tabular}

Legenda: (-) ausência, (+) baixa prevalência, (++) moderada prevalência e (+++) alta prevalência. Fonte: os autores.

A análise das lâminas fora positiva contando as células morfologicamente semelhante a $M$. pachydermatis/lâmina, considerando a seguinte prevalência: (-) ausência de células compatível / lâmina, (+) baixa prevalência, (++) moderada prevalência e (+++) alta prevalência. Desta forma, o exame apresentou uma incidência de Malassezia significativa, tanto na positividade (Figura 3 e 4), quanto na prevalência (Tabela 01). No presente estudo foi evidenciado que $87 \%$ das lâminas positivas, 6,8\% tiveram uma prevalência alta, seguido de $4,5 \%$ de prevalência moderada e de $2,2 \%$ de prevalência baixa. 

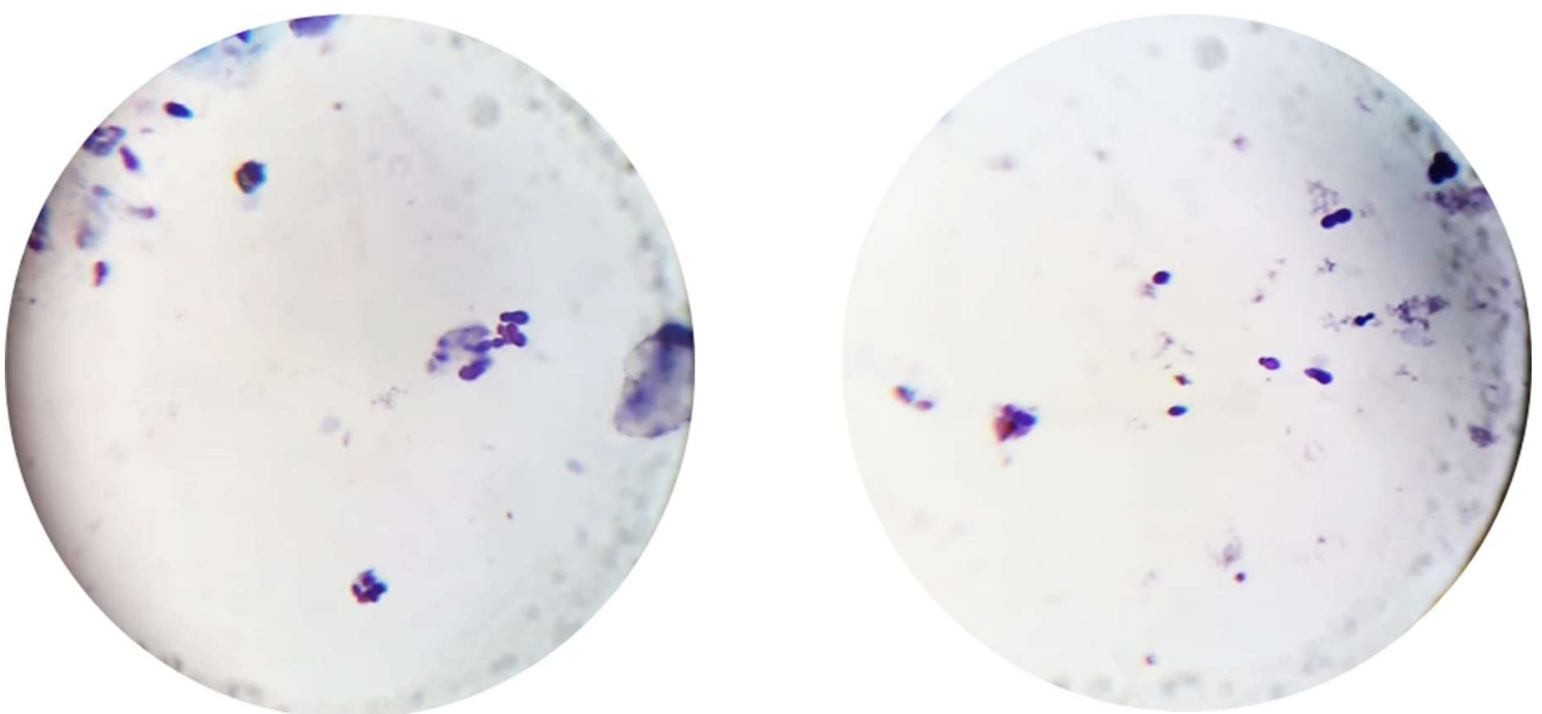

Figura 3 e 4: Presença de Malassezia sp. nas amostras examinadas.

Os cães apresentavam infecções no ouvido interno (otite), emagrecimento, dermatite, presença de ferimentos e alopecias. Outra característica marcante foi o resultado positivo para leishmaniose pelo teste rápido, confirmando a presença de outra patogenia nos cães amostrados.

Segundo Moura e colaboradores (2010), a Malassezia pachydermatis é um microrganismo fúngico mais encontrado no conduto auditivo de cães. Essa infecção pode estar sozinha ou associada a outras patologias, comportamento oportunista atribuído a levedura, desse modo a otite externa é um dos casos mais comuns manifestado em pequenos animais (SILVA NASCENTE et al., 2010).

A baixa na imunidade favorece o crescimento das leveduras, a periodicidade é observada em indivíduos imunodeprimidos, visto que a contaminação por Malassezia podem ser secundárias a outras doenças, tais como, leishmaniose, babesiose, Pitiríase versicolor, dermatite seborreica e papilomatose (CHAVES, 2010).

Sampaio e colaboradores (2011) relata o acometimento de dermatite seborreica causada pela levedura Malassezia em indivíduos contaminados com HIV e isso ocorre devido há alterações significativas nas frações dos lipídios nos pacientes HIV positivos, como uma redução do esqualeno e um aumento do colesterol e de ésteres do colesterol.

Segundo Vaz et al. (2002) a prevalência de Malassezia spp em cães sadios se dá por ela ser uma levedura comensal e não patogênica, $62 \%$ das suas amostras foram positivas nos cães sem patogenia. E em sua pesquisa foi utilizado dois métodos de análise, o direto e o cultivo em meio Ágar Sabouraud enriquecido com óleo de oliva, otimizando o diagnóstico, visto que foi observado resultados negativos no exame direto e positivo no cultivo da mesma amostra.

Possebon et al. (2015) defende que a Malassezia pachydermatis é um habitante natural da microbiota e casualmente torna-se patogênica, sendo assim é um microrganismo oportunista do meato acústico externo de cães e gatos. E desde os primeiros relatos do aparecimento desta levedura na pele, sua presença foi associação com a infecção cutânea em humanos. 
Por outro lado, nos estudos realizados por Machado et al. (2004) a Malassezia pachydermatis está associada à atopia (dermatite canina), que em seu trabalho foi possível constatar $39,5 \%$ de culturas positivas para a levedura relacionado com a atopia, constatando a teoria de que a levedura de fato seja oportunista.

Para ter um diagnóstico mais preciso da Malassezia pachydermatis é preciso que seja feito alguns exames laboratoriais confirmatórios, entre eles podemos citar o citológico, que consiste em avaliar o exsudado auricular. Campos (2011) ressalta em sua pesquisa que através desse exame é possível determinar os agentes infecciosos existente no canal auditivo. A citologia é apontada como um exame de diagnóstico simples, hábil e de baixo custo propiciando um resultado ágil.

Outro exame que também pode diagnosticar e fazer a identificação das espécies de Malassezia é o cultivo, onde é imprescindível iniciar seu cultivo em ágar Sabouraud a $32^{\circ} \mathrm{C}$, com uma discreta camada de óleo de oliva como fonte de lipídios. Outro meio de cultura que pode ser utilizado é Dixon (MARASCHIN et al., 2008).

Para identificar a espécie $M$. pachydermatis basta avaliar sua não dependência de lipídios, e isso é possível pelo seu crescimento no meio ágar Sabouraud sem a adição de ácidos graxos. Por outro lado, nas espécies lipodependentes sua identificação se dá pelas suas habilidades de assimilarem ácidos graxos (Tweens 20, 40, 60 e 80) (PRADO, 2007).

Segundo Coutinho (2003), os métodos moleculares de cariotipagem e PCR têm se revelado fidedigno na separação das espécies, entretanto, essas técnicas são pouco aplicáveis à rotina de análise microbiológica, continuando ainda, os diagnósticos morfológicos microscópicos e as características fisiológicas das leveduras como técnica mais acessível na aplicação direta à rotina laboratorial.

Assim, segundo Breitwieser (1997), pode acontecer do exame direto ter resultado negativo, e o cultivo ter resultado positivo, e se o clínico não utilizar do cultivo para Malassezia, é capaz de avançar a otite para cronicidade em alguns cães.

As causas de otites e dermatites são multifatoriais, que podem ser provocadas por mudanças no $\mathrm{pH}$, na umidade e na temperatura, facilitando o aumento dos agentes secundários e oportunistas, e esses fatores prejudica a ação do tratamento. A Malassezia pachydermatis é um microrganismo residente natural dos ouvidos e da pele dos cães, quando se torna oportunista é necessário um tratamento demorado, o fungo é uma levedura oportunista e sua patogenia manifesta alta contaminação (REOLON et al., 2011).

Segundo Miranda (2004), o tratamento das dermatites causadas pela Malassezia ssp, é considerada simples, vai depender da extensão da lesão, idade e doenças existes do paciente. Os medicamentos tópicos são considerados a melhor escolha em crianças e se houver poucas lesões, quando não há um resultado favorável na medicação tópica, passa para a medicação sistêmica.

Braz et al. (2014), apresenta em seu estudo novos métodos para sanar essa doença, ao utilizar o aparelho gerador de alta frequência e o aparelho de vapor de ozônio. $\mathrm{O}$ aparelho gerador de alta frequência já está sendo empregado há algum tempo com o objetivo antisséptico, germicida, fungicida e bactericida por conter ozônio $\left(\mathrm{O}_{3}\right)$, que atua como esterilizante, e ele possui três métodos de aplicação: efluviação, faiscamento e saturação. O ozônio criado no aparelho de alta frequência age como fungicida nas colônias 
que estão na superfície cutânea. O gás ozônio agride a parede celular dos microrganismos, passando para seu interior e ocasionando oxidação dos aminoácidos e ácidos nucléicos. O ozônio possui ação sobre fungos, bactérias e vírus é classificado como um microbicida.

O diagnóstico da Malassezia pode ser feito pelo exame direto, pelo meio de cultura, porém o exame direto, em algumas vezes, pode fornecer um resultado falso negativo por não haver quantidades significativas de leveduras, enquanto na cultura há crescimento das colônias. Outro método que contribui no diagnóstico e identificação das espécies é a técnica de PCR (Reação em Cadeia da Polimerase), onde é observado a diferença nas cadeias de DNA dessas leveduras.

Embora seja um parasita oportunista, o tratamento da Malassezia inicializa com medicamentos tópicos, em caso mais graves se introduz medicamento sistêmico, em casos mais extremos são utilizados aparelho gerador de alta frequência e o aparelho de vapor de ozônio para controle biológico.

\section{CONCLUSÃO}

Pode-se concluir que das espécies de Malassezia, a M. pachydermatis é a que mais acomete cães e humanos por ser um microrganismo da microbiota natural causando patogenia em associação a outras enfermidades. É possível que a espécie encontrada nos cães amostrados seja essa já que é a mais comum. Sua prevalência em ambos casos é causada pela baixa imunidade do hospedeiro aliado ao aumento da temperatura e da umidade, tornando um ambiente propício para o seu crescimento.

A higienização em animais de estimação deve ser constante, evitando a prevalência de doenças fúngicas oportunistas, acometendo humanos acidentalmente no processo. As zoonoses devem ser tratadas como prioridade no manejo adequado de animais doentes buscando a cura e manutenção da saúde das populações.

AGRADECIMENTOS: Agradecemos a todos os envolvidos na pesquisa, em especial, aos funcionários da Unidade de Controle de Zoonoses de Guaraí (TO) pelo apoio, pela recepção e pela paciência. Aos alunos de Ciências Biológicas e Biomedicina do Instituto Educacional Santa Catarina/Faculdade Guaraí que contribuíram de alguma maneira em um dos processos da pesquisa.

\section{REFERÊNCIAS}

BRAZ, C. E. C.; CUNHA, P. S.; NUNES, R. D.; HERRERA, S. D. C.; SILVA JÚNIOR, D. S.; CARLOTTO, H. S.. Aplicação da alta frequência e do vapor de ozônio no fungo Malassezia spp. Amazônia: Science \& Health, v.2, n.2, p.29-34, 2014.

BREITWIESER, F.. Results of bacteriologic and mycologic investigations of otitis média in dogs. Tierarztliche Praxis, v.25, n.3, p.257-260, 1997.

CAMPOS, T.. Perfil de resistência de bactérias causadoras de otite externa em cães em Porto Alegre - RS. Mogografia (Graduação em Medicina Veterinária) - Universidade Federal Do Rio Grande Do Sul, Porto Alegre, 2011.
CHAVES, C.. Relação entre Malassezia pachydermatis e cães sorologicamente positivos com leishmaniose visceral. Dissertação. Dissertação (Mestrado em Ciência Veterinária) - Universidade Federal Rural de Pernambuco, Recife, 2010.

COUTINHO, S. D.. Malasseziose: a necessidade de se pesquisar as espécies lipodependentes e medicina veterinária. MEDVEP. Rev. cient. Med. Vet., v.1, n.1, p.7073, 2003

FRAMIL, V. M. D. S.; MELHEM, M. S.; SZESZS, M. W.; CORNETA, E. C.; ZAITZ, C.. Pitiríase versicolor: isolamento e identificação das principais espécies de Malassezia. An. bras. dermatol, v.85, n.1, p.111-114, 2010. 
GUILLOT, J.; BOND, R.. Malassezia pachydermatis: uma revisão. Micologia Médica, v.37, n.5, p.295-306, 1999.

HIRAI, A.; KANO, R.; MAKIMURA, K.; DUARTE, E. R.; HAMDAN, J. S.; LACHANCE, M. A.; HASEGAWA, A. Malassezia nana sp. nov., a novel lipid-dependent yeast species isolated from animals. International journal of systematic and evolutionary microbiology, v.54, n.2, p.623627, 2004

LEITE, J. J. G.. Caracterização fenotípica, perfil de sensibilidade antifúngica e estocagem de Malassezia spp. Revista Diálogos Acadêmicos, v.3, n.2, 2016

MACHADO, M. L. S.; APPELT, C. E.; FERREIRO, L. Dermatófitos e leveduras isolados da pele de cães com dermatopatias diversas. Acta scientiae veterinariae. Porto Alegre, v.32, n.3, p.225-232, 2004.

MARASCHIN, M. M.; SPADER, T.; MARIO, D. A. N.; ROSSATO, L.; LOPES, P. G. M.. Infecções causadas por Malassezia: novas abordagens. Saúde (Santa Maria), v.34, n.1-2, p.4-8, 2008.

MCVEY, S.; KENNEDY, M.; CHENGAPPA, M. M.. Microbiologia veterinária. 3 ed. Rio de Janeiro: Guanabara Koogan, 2013.

MELCHERT, A.; JEFERY, A. B. S.; GIUFFRIDA, R.. Avaliações citológicas em otites caninas por Malassezia Spp.: Estudo Retrospectivo. Colloquium Agrariae, v.7, n.2, p.27-34, 2011.

MIRANDA, L. G. A.. Identificação de espécies de Malassezia em pacientes com Pitiríase versicolor atendidos no ambulatório de dermatologia CAME-Primavera em João Pessoa-PB. Dissertação (Mestrado em Medicina Tropical) Universidade Federal de Pernambuco, Recife, 2004.

MOURA, E. S. R.; SOUZA FONSECA, Z. A. A.; FEIJÓ, F. M. C.; FILGUEIRA, K. D.; SILVA, J. B. A.. Isolamento e identificação de microrganismos causadores de otites em cães. PUBVET, v.4, p.717-722, 2010.

NOBRE, M. O.; MEIRELES, M. C. A.; GASPAR, L. F.; PEREIRA, D.; SCHRAMM, R.; SCHUCH, L. F.; SOUZA, L.. Malassezia pachydermatis e outros agentes infecciosos nas otites externas e dermatites em cães. Ciência rural, v.28, n.3, p.447-452, 1998

POSSEBON, K. F.; KAISER, T. S.; MARTINS, L. R. V.. Agentes microbianos isolados de otite externa em cães. In: SEMINÁRIO DE INICIAÇÃO CIENTÍFICA, 23. Anais. Unijuí, 2015.

PRADO, M. R.. Isolamento de Microsporum canis, Malassezia spp. e Candida tropicalis em cães: um destaque para teste de sensibilidade de Malassezia pachydermatis in vitro. Tese (Doutorado em Ciências Veterinárias) Universidade Estadual do Ceará, 2007.
PRADO, M. R.; BRILHANTE, R. S.; SIDRIM, J. J.; ROCHA, M. F... Malassezia spp. em humanos e pequenos animais: uma abordagem teórica. Revista Portuguesa de Ciências Veterinárias, v.102, p.207-214, 2007.

REOLON, M.; NORONHA, F.; DALL'ASTA, L. B.; OLIVEIRA, M.; BERNARDDI, E.; SILVA, A. A.; MARTINS, D. B.; OLIVEIRA, Z. B.; ALCÂNTARA, P.. Otite por Malassezia em cão: relato de caso. In: Seminário Interinstitucional de Ensino, pesquisa e extensão, 16. Anais. Cruz Alta: UNICRUZ, 2011.

SAMPAIO, A. L. S. B.; MAMERI, Â. C. A.; VARGAS, T. J. D. S.; NUNES, A. P.; CARNEIRO, S. C. D. S.. Dermatite seborreica. An. Bras. Dermatol, v.86, n.6, p.1061-1074, 2011.

SANTIN, R.; GIORDANI, C.; MADRID, I. M.; MATOS, C. B. D.; FREITAG, R. A.; MEIRELES, M. C. A.; MELLO, J. R. B. D.. Atividade antifúngica do óleo essencial de Origanum vulgare frente a Malassezia pachydermatis. Arquivo brasileiro de medicina veterinária e zootecnia, Belo Horizonte, v.66, n.2, p.367-373, 2014

SCHLOTTFELDT, F. D. S.; TRAMONTIN, S. W.; NAPPI, B. P., SANTOS, J. I. D.. Reclassification of Malassezia species: a review of its clinical and laboratory significance. Jornal Brasileiro de Patologia e Medicina Laboratorial, v.38, n.3, p.199-204, 2002.

SILVA NASCENTE, P.; SANTIN, R.; MEINERZ, A. R. M.; MARTINS, A. A.; MEIRELES, M. C. A.; MELLO, J. R. B.. Estudo da frequência de Malassezia pachydermatis em cães com otite externa no Rio Grande do Sul. Ciência Animal Brasileira, v.11, n.3, p.527-536, 2010.

SUGITA, T.; TAJIMA, M.; TAKASHIMA, M.; AMAYA, M.; SAITO, M.; TSUBOI, R.; NISHIKAWA, A.. A new yeast, Malassezia yamatoensis, isolated from a patient with seborrheic dermatitis, and its distribution in patients and healthy subjects. Microbiology and immunology, v.48, n.8, p.579583, 2004

SUGITA, T.; TAKASHIMA, M.; KODAMA, M.; TSUBOI, R.; NISHIKAWA, A.. Description of a new yeast species, Malassezia japonica, and its detection in patients with atopic dermatitis and healthy subjects. Journal of clinical Microbiology, v.41, n.10, p.4695-4699, 2003.

TÁRTARA, G. P.. Malassezia spp. en Perros Y Gatos, Un Enfoque Integral. In: CONGRESO NACIONAL DE AVEACA, 11. Anais. 2011.

VAZ, A. K., ZAMBAN, A. L. M.. Prevalence of Malassezia sp. in the ears of asymptomatic dogs and dogs with otitis examined at the veterinary hospital clinic in Lages/SC from October to December 2000. Revista de Ciencias Agroveterinarias, v.1, n.1, p.16-20, 2002.

A CBPC - Companhia Brasileira de Produção Científica (CNPJ: 11.221.422/0001-03) detém os direitos materiais desta publicação. Os direitos referem-se à publicação do trabalho em qualquer parte do mundo, incluindo os direitos às renovações, expansões e disseminações da contribuição, bem como outros direitos subsidiários. Todos os trabalhos publicados eletronicamente poderão posteriormente ser publicados em coletâneas impressas sob coordenação da Sapientiae Publishing, da Companhia Brasileira de Produção Científica e seus parceiros autorizados. Os (as) autores (as) preservam os direitos autorais, mas não têm permissão para a publicação da contribuição em outro meio, impresso ou digital, em português ou em tradução. 